\title{
FILOLOOGIA, FILOSOOFIA JA TÕDE
}

\author{
NEEME NÄRIPÄ
}

\begin{abstract}
Oel kevadel osalesin ühe kirjandusteadusliku teadustöö kaitsmisel. Oponendiks oli kutsutud filosoof, sest lähenemine oli interdistsiplinaarne, kirjandusteksti analüüsiks kasutati filosoofilisi mõisteid. Oponent oli kriitiline ning heitis töö autorile ette järjekindlusetust teoreetilises plaanis: autor ei olnud mõisteid ammendavalt defineerinud ühe või teise filosoofilise süsteemi raames ega kasutanud neid siis nendele definitsioonidele toetudes. Mulle meenus sarnane olukord kunagistelt konverentsidelt ja doktoriseminaridest, kuhu kutsusin oma ettekannet kuulama filosoofiataustaga sõpru, sest üritasin toona siduda retoorilist stasiseteooriat (vt allpool) filosoofiliste kategooriatega. See ei läinud väga hästi, kuna hoolimata teatud määral kattuvatest nimetustest on stasised ja kategooriad eri asjad, kuigi neid on üritatud ühte patta panna nii antiikajal kui ka hiljem.

Säärane filosoofia mängureeglitest tulenev süüdistus definitsioonide vastu eksimises ja järjekindlusetuses kõlab täiesti mõistlikuna. Kuid enamasti ehmatab see natuke filoloogi, kellel on tunne, et sai ju tehtud põhjalik analüüs ja ka mõistete endi puhul pole otseselt eksitud millegi vastu: kõik on must valgel kirjas, jäetud on ainult sukeldumata ühe või teise definitsioonisüviku põhjani või oldud ehk pisut liiga kergeusklik. Esiteks on sõnad, mida me kuuleme, loeme, räägime ja kirjutame, peale mõistete ka ainult sõnad; teiseks aga pole mõistete definitsioonid olnud kogu aeg nii selged, kui nad tunduvad praegu.
\end{abstract}

\section{Süütud sõnad}

V ja IV sajandi vahetusel eKr võistlesid Ateenas rahva õpetamises kolm osapoolt: sofistid, Isokrates ja Platon. Kuulsaim esimese põlvkonna sofist oli Gorgias Leontinoist. Platon kujutab teda dialoogis „Gorgias” mõjusa kõnemehena, keda ei huvita niivõrd tõde ja õiglus kui veenvus, ükskõik mis hinnaga. „Phileboses" ütleb Platon, et Gorgias pidas veenmiskunsti kaugelt paremaks kõigist teistest, sest kõik allub orjana sellele kunstile vabatahtlikult, mitte jõuga (Burnet 1967-1968: Pl. Phlb. 58a-b). Muuhulgas omistatakse Gorgiasele ainult parafraasidena säilinud teos pealkirjaga „Mitteolevast või loodusest” (vrd Mutschmann 1914: Sextus Empiricus, Adversus mathematicos, 7.65), kus ta väitis, et midagi ei ole olemas, või kui miski on olemas, siis ei ole võimalik seda teada, või kui seda oleks võimalik teada, siis ei ole võimalik seda väljendada ega seletada (Bons 2007: 37-38; Mutschmann 1914: Sextus Empiricus,

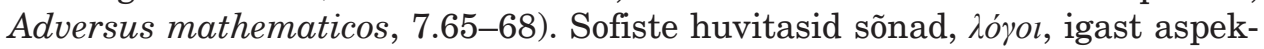
tist, nad uurisid nii argumentatsiooni, grammatikat kui ka stiili (Bons 2007: 39). Gorgiase traktaati mitteolevast saab pidada niisuguse lähenemise tour de force'iks: sõnade abil on võimalik veenda ka milleski nii ebaintuitiivses kui 
mitteolemine. Nagu näha, tegelesid sofistid peale absurdsete väidete esitamise ka tänapäeva mõistes filoloogiaga. Nad uskusid sõnade jõudu: Gorgias lausub „Kiidukõnes Helenale”, et kõne on suur valitseja, kes tilleima ja nähtamatuima kehaga teeb jumalikemaid tegusid (DK: fr. 82 B 11).

Sofistidega võistles Isokrates, kes on muu hulgas tuntud selle poolest, et rajas u 390 eKr esimese retoorikakooli. Platoni jaoks oli Isokrates üks väheseid kõnemehi, kellest ta mingil määral lugu pidas. Platoni dialoogi „Phaidros” lõpus ütleb Sokrates, et noor Isokrates võib saada paremaks kõigist kõnemeestest, mingi jumalikum hoog võib aga viia teda veel suuremate asjade poole, sest tema mõistuses on loomu poolest tarkusearmastus ehk filosoofia (Burnet 1967-1968: Pl. Phdr. 279a). Isokrates ründas oma kõneõpetajatest konkurente kõnes „Sofistide vastu”, öeldes, et sofistid üritavad odava raha eest õpetada voorust, õnne ja õiglust (Mathieu, Brémond 1963: Isoc. 13.4-5). Kõnes „Antidosis" peab ta aga ka nn filosoofia valdkonda kuuluvaid ontoloogilisi ja epistemoloogilisi arutlusi mõttetuks ajaraiskamiseks (Mathieu, Brémond 1966: Isoc. 15.268-9), mainides ennekõike presokraatikuid, kuid viidates ilmselt ühtlasi Platoni Akadeemiale (Kennedy 1994: 47).

Ärgem aga unustagem, et Isokratese jaoks oli nii presokraatiline kui ka akadeemiline filosoofia ajaraiskamine. Vähe sellest, kõnes „Sofistide vastu”

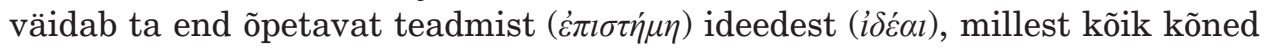
koosnevad (Mathieu, Brémond 1963: Isoc. 13.16). Samuti ütleb ta, et tema õpilased tegelevad kõnekunsti õppides filosofeerimisega, nad on oi $\varphi \imath \lambda o \sigma o \varphi \circ \tilde{v} v \tau \varepsilon \varsigma$

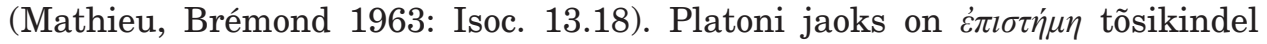
teadmine tõest ning ideed ainus, mis on olemas päriselt, igavesti ja muutumatuna, filosoofia seevastu tegeleb päriselt olevaga (Burnet 1967-1968: Pl. Phdr. 249 b-c). Neid sõnu kasutades ei kummuta aga Isokrates sugugi Platoni epistemoloogiat või ideedeõpetust. Ta kasutab lihtsalt kreeka keeles leiduvaid sõnu ajal, kui need ei kandnud veel aastatuhandete jooksul kuhjunud filosoofiliste definitsioonide koormat, kui filosoofia ei olnud veel filosoofia, vaid võis olla kõnekunstiga tegelemine.

Seejuures ei saa ka päriselt väita, et Isokratesel oleks tegu nn tavakeelse kasutusega, Platonil aga konkreetsete terminitega. Nagu nägime, olid need traditsioonid omavahel dialoogis. Isokratese fraasi „teadmine ideede kohta, millest me kõnesid koostame" on peaaegu võimatu lugeda tavakeelsena, ilma vihjeta Platonile. Samal ajal on Isokratese teadmine ja ideed kindlasti midagi muud, st teistmoodi defineeritavad kui Platoni omad. Teiselt poolt seisid Platoni teadmine ning idee $\mathrm{V}$ ja IV sajandil eKr tavakeele mõisteile oluliselt lähemal kui filosoofia oskussõnad tänapäeval. Ettekujutusele Platoni ideedest polnud lisandunud kristlikku uusplatoonilist kihti, rääkimata Karl Friedrich Tennemanni katsest selgitada välja dialoogide ajaline järjestus ja kirjeldada Platoni õpetuse arengut ning Friedrich Schleiermacheri soovist panna paika üks ja koherentne Platoni õpetus ning eristada ehtsaid dialooge ebaehtsaist (Lamm 2000: 206-239).

V ja IV sajandil eKr olid definitsioonisüvikud palju madalamad ja mõistete koorem palju kergem. Võim ja hierarhiad ning nendest tulenevad hinnangud alles hakkasid välja kujunema. 


\section{Võitjate ajalugu}

Tänapäeval saab sofistid, Isokratese ja Platoni üsna lihtsalt seada hinnanguliste konnotatsioonide järgi pingeritta. Sofism ja sofistika on peaaegu sõimusõnad, Platon on aga õhtumaise filosoofia kindel tugisammas. Mälestus Isokratesest on meie praeguses kultuuris ähmasem, kuid ilmselt paigutub ta hinnanguliselt nende kahe pooluse vahele: tema sofistliku relativismi kriitika on tervitatav, kuid ta õpetas ikkagi retoorikat, mis pole filosoofiliselt eriti tõsiselt võetav.

Kuidas põhjendada seda, et Platoni mõisted on paremad ja kuidagi tõele lähemal? Üks võimalus oleks, et tõde ongi platooniline, toimub mõtlemise progress n-ö tõe suunas, kvalitatiivne areng. See tähendab, et iga uue uuringuga saame järjest täpsemalt aru, „kuidas miski tegelikult on”. Nii armastatakse aeg-ajalt mõelda täppisteadustes ja ka filosoofias. Selline vaade eeldab laias laastus usku nn täiuslike ideede olemasollu ning platoonilise traditsiooni omaks võtmist: iga asja puhul on võimalik liikuda lähemale ühesele tõele ja kuigi me sinna oma ebatäiuslikkuses kunagi päriselt kohale ei jõua, peaksime pidevalt selle poole püüdlema. Kui meile Platon ei meeldi, kui me tunnistame mingitki kultuurilist paljusust, siis vangub juba ka ettekujutus kvalitatiivsest tõe poole liikumisest. Piltlikult öeldes, kui meil on Platon, siis milleks meile üldse Isokrates või sofistid.

Tõsiusklikku platoonikut on tänapäeval raske leida. Traditsioonilist platoonilist tõde õonestavad lausa Platoni-uuringud ise. Alain Badiou avaldas hiljuti Platoni „Politeia” (hüper)tõlke (Badiou 2014), kus mainitakse Hegelit ja Hitlerit, Leninit, Marxi ja Mao Zedongi, Friedrich Nietzschet ja Sigmund Freudi ning mitmeid teisi eri ajastute mõtlejaid. Lisaks Platoni vennale Glaukonile esineb vestluses ta fiktiivne õde Amantha, kes asendab Adeimantost. Platoni viis riigikorda ja neile vastavat inimtüüpi on Badiou järgi kommunistlik, timokraatlik, oligarhiline, demokraatlik ja türanlik ehk fašistlik - parim, onnelikem ja õiglaseim on neist esimene, ebaõiglaseim ja halvim aga viimane (cf. Burnet 1967-1968: Pl. R. 580b-c; Badiou 2014: 500-501). Kui võtta aluseks kvalitatiivne liikumine tõe suunas, siis peaks aga ka Badiou tõlgendus mingil viisil olema täpsem kui varasemad. Ometi on raske uskuda, et kommunistliku tõlgendusega oleksime jõudnud Platonile kuidagi lähemale kui varasemate põlvkondade uurijad.

Samas on võimalik, et Badiouga oleme ikkagi jõudnud mingis mõttes lähemale tõele, kui ka mitte Platonile, ainult teistkaudu. Selleks peame loobuma platoonilisest idealismist ning uskuma, et aja jooksul teadmiste ja tekstide kuhjudes saab midagi selgemaks tänu nii-öelda kvantiteedile. Iga uus tekst ja tõlgendus on sel juhul väike lisandus tervikpilti, mis olekski tõde või see, kuidas miski tegelikult on. Mosaiigi kõik tükid ei saa kunagi paika, sest neid on lõputu arv, kuid pilt järjest täieneb. Sellise lähenemisega kipuvad nõustuma tänapäeval filoloogid.

Niisuguse vaatenurga probleem on aga see, et kõik tükid peaksid olema võrdsed: nii Isokrates, Platon kui ka Badiou, kes kõik kasutavad samu termineid, peaksid pilti ühevõrra täiendama ning üht ei saaks pidada teisest õigemaks. Samal ajal armastab kultuur hierarhiaid: Platon on parem kui Isokrates, skolastika oli eksitee ja mis saab Badioust, pole veel selge. Tekste peaks 
olema võimalik pingeritta seada, mõned neist kvalifitseeruvad teaduseks, teised on aga lihtsalt puhas jampsimine. Kultuur tegeleb pideva selektsiooniga, millest rohkem ja millest vähem rääkida, mida säilitada ja mida unustada.

Kui teha viimane katse Platonit kaitsta, siis võiksime öelda, et Platoni mõisted on paremad ja tõele lähemal, sest need on põhjalikumalt defineeritud ja läbimõeldud. Põhjalikkus on kahtlemata voorus, kuid see ei tee mõisteid ilmtingimata õigemaks, ei lähenda neid sellele, „kuidas miski tegelikult on”. Skolastiline sääsekurnamine võib olla väga põhjalik, kuid tänapäeva kultuuri kontekstis ei päästa see teda ikkagi.

Niisiis kui me hülgame ettekujutuse täiuslikest ideedest, peaksime teise võimalusena omaks võtma, et hierarhiaid ei kujunda mitte tõde, vaid nn võitjate ajalugu. Tõde asendub võimuga. Samavõrra tähtis kui see, kuidas Badiou Platonit ümber kirjutas, milliseid teri sõkaldest eraldas ja milliseid juurde mõtles, on see, et ta kirjutas ümber just Platonit. Mitte ainult ei muudeta maoistliku kommunismi abil ühe kultuuri ühe põlvkonna jaoks tõeseks Platonit, vaid samuti muudetakse Platoni abil tõeseks maoistlik kommunism, seda mitte ainult ühe põlvkonna jaoks, vaid kuniks valitseb platonistlik tõde, seejuures ka tagasiulatuvalt üle kahe aastatuhande. Võitjate ajalugu ei kujunda mitte ainult hierarhiaid, vaid nende kaudu ka tõde: kui ei ole täiuslikke ideid, vaid tõele läheneb mõtete ja tekstide kogusumma, siis kujundavad tõde mäletamine ja unustamine. Kui miski on päriselt ära unustatud, on seda peaaegu võimatu tagasi tuua.

Klassikalises Ateenas esines kaks tähelepanuväärset juhtumit, kus võim tegeles mälestuste selektsiooniga. Esimene neist oli otseselt seotud loominguga: 494. aastal eKr trahviti näitekirjanik Phrynichost näidendi „Mileetose vallutamine" eest, kuna ta meenutas seal halba, nimelt seda, kuidas samal aastal pärslased Joonia ülestõusu maha surusid (Legrand 1963: Hdt. 6.21). Sellesama otsusega keelati näidendit iialgi uuesti lavastada. Nõnda pole "Mileetose vallutamine" meie ajani säilinud, küll aga on seda teine ajalooline tragöödia, Aischylose „Pärslased”, kus kujutatakse samuti kreeklaste ja pärslaste vastasseisu - ainult kreeklastel läheb seal paremini.

Teine kuulus kultuuriline mälestuste selektsioon toimus 403. aastal eKr, kui Ateenas kukutati Kolmekümne türannia: demokraadid andsid välja nii demokraate, oligarhe kui ka avalikust elus kõrvale hoidnud isikuid siduva korralduse „mitte mäletada halba”, $\mu \grave{\eta} \mu \nu \eta \sigma ı \kappa \alpha \kappa \varepsilon \tilde{v}$ (Loraux 2006: 147-152). See lähenemine erineb kontseptuaalselt Platoni omast, kelle jaoks oli mäletamine, $\dot{\alpha} v \alpha ́ \mu \nu \eta \sigma \iota \varsigma$, viis leida enda seest üles tõeline teadmine, hüljates väärarvamused. Ometi tegelevad mõlemad, nii üleskutsed unustada kui ka mäletada, mõtete ja tekstide hierarhiseerimisega ning omamoodi tõe poole püüdlemise ning selle kujundamise ja kehtestamisega. Filoloogia on võimuhierarhiate teenistuses, samuti ka filosoofia, kui me just ei usu päriselt ideede kaemisse. Järgnevalt tuleb juttu ühest konkreetsest juhtumist, kus põrkuvad filoloogia ja filosoofia ning esineb küsimus, kas tuleks väiteid kuidagi hierarhiseerida või mitte. 


\section{Stasise-juhtum}

Minu isiklikud probleemid filosoofidega on ennekõike seotud vanakreeka stasise mõistega ( $\sigma \tau \dot{\alpha} \sigma l \varsigma)$. Stasis on kreeka keeles paljude ja esmapilgul vastandlike tähendustega sõna, mille tüvi esineb võõrsõnades, nagu ekstaas või hüpostaas. H. G. Liddelli, R. Scotti ja H. S. Jonesi kreeka-inglise leksikoni järgi on sõnal olemas nii seismisele viitavad tähendused, nagu 'positsioon, asend, asetus', kui ka konfliktiga seotud, nagu 'vastasseis, erimeelsus' jms; neile liituvad veel spetsiaalselt poliitilised tähendused, nagu 'partei', 'võitlev partei' ja 'parteide võitlus' (LSJ: 1643). Stasis on ka retoorikateooria termin, mis tähistab nn vaidlusküsimust, seda, mille üle vaieldakse (sks Streitpunkt, vrd Hoppmann 2008: 93). Stasiseteooria rajajaks peetakse Hermagorast

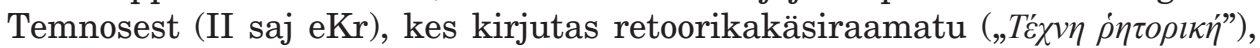
kus rääkis neljast eri liiki stasisest, mille kreekakeelsed nimed on vastavalt

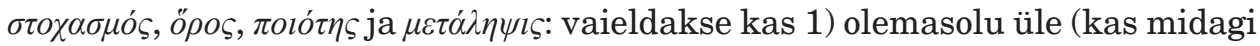
toimus), 2) definitsiooni üle (mis see on, mis toimus), 3) kvaliteedi üle (missugune see on, mis toimus) või 4) vaidluse enda üle, n-ö kompetentsi üle (kas millegi üle saab neil tingimustel vaielda). ${ }^{1}$ Üldiselt on stasised kujuteldavad väite ja vastuväite kohtumisena, kuid võivad olla formuleeritud ka küsimustena, stasiste nimetused on substantiivid. ${ }^{2}$ Siiani on tegu puhta retoorilise õpetusega, mis vähemalt eksplitsiitselt ei puuduta filosoofilist traditsiooni. Edasi aga näeme, kuidas asjasse segatakse filosoofiaterminid.

Nimelt ütleb kõigepealt I sajandi lõpus pKr Marcus Fabius Quintilianus senisest retoorikateooriast ülevaadet andvas teoses „Institutio oratoria”, et ülalkirjeldatud stasised on seostatavad Aristotelese esimese nelja filosoofilise kategooriaga (Winterbottom 1970: Quint. Inst. 3.6.23-25). Aristoteles jaotas teoses „Kategooriad” selle, mida saab öelda subjekti kohta lihtsalt, kümneks

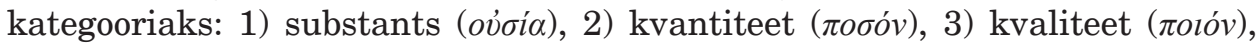

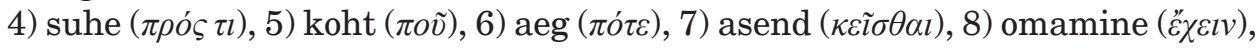
9) tegemine $(\pi o l \varepsilon \tilde{\imath} v), 10)$ talumine ( $\pi \dot{\alpha} \sigma \chi \varepsilon l v)$ (Minio-Paluello 1966: Arist. Cat. $1 \mathrm{~b} 25$ jj). Asi ei piirdu aga ainult Quintilianusega. V sajandil pKr kirjutab Syrianos kommentaari kuulsaimale stasiseteooriaga tegelevale teosele, mille autoriks on II ja III sajandil pKr elanud Hermogenes Tarsosest. ${ }^{3}$ See kommentaar seostab samuti kõneteooria stasiseid Aristotelese kategooriatega. Syrianos arutleb, kas substantsi kategooria vastab esimesele või teisele stasisele, ning ütleb, et kõneteoreetikud jaotasid loendamatud tõendusväited ( $\dot{\alpha} \pi \circ \delta \varepsilon i \xi \varepsilon l \varsigma)$ neljateist-

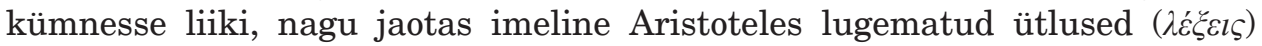
kümnesse kategooriasse (Rabe 1893: Syrian. In Hermog. 55.5-15, 58.18-59.2). Selle võimaliku seose stasiste ja filosoofiliste kategooriate vahel on - ilmselt antiikautoritest inspireerituna - üles korjanud ka üksikud stasiseid käsitleva

${ }^{1}$ Hermagorase käsiraamat on säilinud fragmentaarselt, vanimateks allikateks on anonüümne „Rhetorica ad Herennium” ja Cicero „De inventione”. Põhjaliku eessõnaga uusima fragmendikogumiku väljaandjaks on Frédérique Woerther (2012).

${ }^{2}$ Kas stasiseks peetakse ühe poole esimest väidet, millele peab järgnema vastuväide, ühe poole väidet koos teise poole vastuväitega või väitest ja vastuväitest sündinud küsimust, on uurinud Malcolm Heath, kes jõuab järeldusele, et autorid ei ole selles osas koherentsed, nt Cicero teostes on viiteid kõigile kolmele võimalusele (Heath 1994).

${ }^{3}$ Ülevaate Hermogenese stasiseteooriast ja tema teose tõlke leiab eesti keeles ajakirjast Akadeemia, vt Näripä 2011; Hermogenes 2011. 
sekundaarkirjanduse autorid, nt Georg Thiele (1893: 47-48), hiljem ka Walther Jäneke (1904: 62-78) ning Ray Nadeau (1959). Suurem osa uurijaid, eriti hilisemad, on sellest seosest siiski targu eemale hoidnud.

Probleem on nimelt selles, et kõnekunsti stasised ja filosoofilised kategooriad on olemuslikult ikkagi pigem erinevad. Stasised kujutavad endast konflikte, kategooriad liigitavad maailma või seda, mida saab selle maailma kohta öelda, kuid seos konfliktiga puudub. Peale selle ei sobi stasiste jaotus hästi kokku vähemalt Aristotelese kategooriate jaotusega. Juba esimese nelja kategooria juures tekib küsimus, kuidas neid stasistega vastavusse viia (nagu nägime Syrianose puhul), rääkimata hädast, mida teha ülejäänud kuue kategooriaga. Viimaks on stasiseteooria jälgi leitud juba Aristotelese „Retoorikas”, kus stasise sõna küll ei kasutata (Cope 1867: 397-400; Nadeau 1959; Liu 1991) - Aristoteles ise nendes kohtades mingeid seoseid kategooriatega ei loo.

Niisiis võiks öelda, et filosoofilisest vaatenurgast on see täielik jama. Filosoofilise diskursuse seisukohast pole kuigi tähtis, mida Quintilianus I sajandil ja Syrianos V sajandil ütlevad, kui sellele räägib vastu kogu filosoofiline traditsioon, mis - rääkimata sellest, et ei maini ise kategooriate seost stasistega - peab seda põhimõtteliselt vääraks ja valeks. Stasised ja kategooriad erinevad definitsioonide poolest. ${ }^{4}$ Filosoofil on võimalik käega lüüa Quintilianusele ja Syrianosele ning pidada neid kas tõest kõrvale kallutava eksiõpetuse esitajateks (ülalkirjeldatud platooniline vaatenurk) või siis vähetähtsa panuse andjateks koondpilti, mis ei aita stasiste, kategooriate või tõe mõistmisele eriti kaasa ning tuleks seetõttu pigem unustada (ülalkirjeldatud kvantitatiivne, kuid hierarhiseeriv vaatenurk). Filoloogina ei saa aga ka parima tahtmise juures neist kahest mööda minna: lihtsalt, sest nad on öelnud seda, mida nad on öelnud. Seda ei saa olematuks muuta, sellega tuleb midagi peale hakata.

Olukorda saab võrrelda Isokratese ja Platoni juhtumiga, seejuures hakkab silma nii sarnasusi kui ka erinevusi. Mõlemal juhul puutuvad mingis punktis kokku kaks diskursust. Isokratese ja Platoni kokkupuutepunktideks on ühised oskussõnad, aga ka füüsiliselt IV Kristuse-eelse sajandi Ateena. Ka stasistel ja kategooriatel on oskussõnaline kokkupuutepunkt olemas: kvaliteedistasis kannab nime $\pi$ oı́́ $\eta \varsigma$ (järelliitega tuletatud substantiiv), kvaliteedikategooria

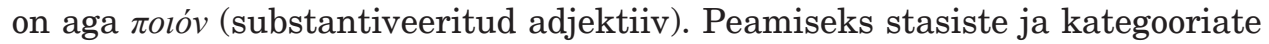
kohtumispaigaks on aga metatekstid.

Oluline erinevus Platoni ja Isokratese ning stasiste ja kategooriate vahel on ajaline aspekt. Isokratese ja Platoni tekstid on üldjoontes samaaegsed ning terminoloogia on sel ajastul alles kujunemas. Seepärast jagavad Platon ja Isokrates omavahel eikellegimaad: kelle omaks saavad sõnad filosoofia, teadmine ja idee. Kõneteoreetikute leeri kuulunud Quintilianus ja Syrianos tegutsesid aga sajandeid pärast imelist stageiralast ja ka pärast Hermago-

\footnotetext{
${ }^{4}$ Stephen Pepper kritiseerib nominaalseid definitsioone nendejäikuse ja preskriptiivsuse pärast, nendes jäävad kõrvale kõik alternatiivsed hüpoteesid, mis kasutavad termineid teisiti. Pepper pakub nominaalse definitsiooni asenduseks välja kirjeldava ehk deskriptiivse definitsiooni, mis tekib kirjelduse kaudu ning on tõene ainult sel määral, kui tõene on kirjeldus, st mitte kunagi täielikult. Deskriptiivne definitsioon on kergesti muutuv, kui muutub või täpsustub kirjeldus. (Pepper 1946)
} 
rast, üritades hõivata võõraid valdusi. Neil erinevail kultuurisituatsioonidel on kaunid geopoliitilised peegeldused. Platoni ajal mäletati veel hästi kreeklaste kolonisatsiooniperioodi, mis oli küll klassikaliseks ajastuks juba lõppenud, kuid kreeka linnad nn eikellegimaal õitsesid. Rooma keisririigi aegu, mil elasid Quintilianus ja Syrianos, oli kogu tuntum maailm juba ära jagatud. Niisamuti oli kultuurikiht paks ja laius kõikjal, kuhu pilk pöörata. Kõik oli enam-vähem korralikult ära defineeritud, seega jäigi enamasti üle ainult asju ümber defineerida, üritada mõisteid ühest kohast teise tõsta.

\section{Lahendusi}

Kuidas siis said Quintilianus ja Syrianos üldse öelda, et stasised on seotud Aristotelese kategooriatega? Oletagem, et tegu polnud siiski lihtsalt rumalate inimestega (filoloogitöö ühe alussamba, tekstikriitika oluline põhimõte on lectio difficilior potior, eelistada tuleb keerulisemat lugemit, mis üldistatuna hoiatab meid tekstide puhul lihtsate lahenduste eest). Oletagem, et stasise mõiste muutus ajas. Algselt tähistas stasis konflikti, kuid Rooma keisririigi ajajärgul konflikti osatähtsus mõiste tähendusväljal vähenes ning ühepoolse väite või seisukoha osatähtsus suurenes. Sellisest arengust annavad tunnistust ka II sajandil pKr tegutsenud Arrianose tekstid, kes tähendas üles oma õpetaja Epiktetose mõtteid. „Õpetuskõnedes” ja „Käsiraamatus” mainitakse filosoofi ja lihtinimese vaateid või hoiakuid maailmas, tähistades neid uudselt sõnaga stasis (Schenkl 1965: Dissertationes 1.21, Enchiridion 48.1.1-2.3). Nende hoiakute ehk stasiste määratluses ei sisaldu Epiktetosel aga viidet vastandumisele, stasise sellisel tähendusel ei ole seost konfliktiga, väite ja vastuväite kohtumisega. Nii sai võimalikuks ka retoorikateooria stasiseid mõista lihtsalt erinevat liiki väiteina, mis lähendas neid oluliselt Aristotelese kategooriatele ning ahvatles kaht süsteemi kokku viima, isegi kui see lõpuni ei õnnestunud. (Näripä 2019)

Ühesõnaga, Quintilianus ja Syrianos vahest ikkagi ei eksi nii rängalt, kui alguses karta võis, vähemalt filoloogilisest vaatenurgast nähtuna. Eksisteerisid kindel aeg ja kontekst, kus stasistel ja kategooriatel oli võimalik üheks saada, vaatamata algselt erinevatele definitsioonidele. Asi on selles, et mõisted on pidevas muutumises. Vähe sellest, mõisted on piiritletud teiste mõistete kaudu, mis on samuti pidevas muutumises. Keel arbitraarse märgisüsteemina õõnestab pidevalt filosoofiat, sest kui muutuvad mõisted, moonduvad ka kunagi hoolikalt konstrueeritud definitsioonid metsikuteks kimäärideks. Me ei saa selle vastu midagi teha ja peame leppima.

Mis tõesse puutub, siis arvan, et sellele pööratakse teaduses natuke liiga suurt tähelepanu, sest võim on ahvatlev. Päris hästi ei tööta ei platooniliste ideede poole liikumine ega ka katsed tükkidest ja tekstidest terviklikku tõde kokku laduda. Tõde on filoloogi jaoks küll olemas, kuid ta on ealt üürike ja kontekstilt kitsas, ta võib meile vahel ainult silma välgatada nagu päikesekiir kiikuvalt peeglilt, kui soodsad tingimused kokku langevad. See, millega me kogu aeg sihipäraselt vaeva näeme, ei ole sugugi tõe poole püüdlemine, ideaalis ka mitte teadlik pingutus mäletada või unustada - vaid pidev tekstide ümberkirjutamine ja mõtete ümbersõnastamine meenutamaks, et millestki on 
võimalik aru saada. Nimelt kohe, kui tekib tunne, et me ei saa mingist mõttest või tekstist aru, läheb see meil meelest, kaob kultuurist. Seda me ju ei tahaks, ega taha ka filosoofid.

\section{Kirjandus}

B a d i o u, Alain 2014. La République de Platon: dialogue en un prologue, seize chapitres et un épilogue. Paris: Frayard/Pluriel.

Bons, A. E. Jeroen 2007. Gorgias the sophist and early rhetoric. - A Companion to Greek Rhetoric. Koost Ian Worthington. Oxford: Blackwell Publishing Ltd, lk 37-46.

Burnet, John 1967-1968. Platonis opera. Kd 2, 3, 4. Oxford: Clarendon Press.

Cope, Edward Meredith 1867. An Introduction to Aristotle's Rhetoric: With Analysis, Notes and Appendices. London-Cambridge: Macmillan and Co.

DK = Di els, Hermann Alexander, Kr a n z, Walther 1966. Die Fragmente der Vorsokratiker. Kd 2. Berlin: Weidmann.

He a th, Malcolm 1994. The substructure of stasis-theory from Hermagoras to Hermogenes. - Classical Quarterly, kd 44, nr 1, lk 114-129.

Hermogenes 2011. Seisudest. Tlk Neeme Näripä. - Akadeemia, nr 8, lk 14031441.

Hoppmann, Michael J. 2008. Argumentative Verteidigung: Grundlegung zu einer mordernen Statuslehre. Berlin: Weidler Buchverlag.

Jä n eke, Walther 1904. De statuum doctrina ab Hermogene tradita: ad rhetoricae historiam symbolae. Leipzig: Univ. Diss.

Kennedy, George A. 1994. A New History of Classical Rhetoric. Princeton, New Jersey: Princeton University Press.

L a m m, Julia A. 2000. Schleiermacher as Plato scholar. - The Journal of Religion, kd 80, nr 2, lk 206-239.

Legrand, Philippe-Ernest 1963. Hérodote. Histoires. Kd 6. Paris: Les Belles Lettres.

Li u, Yameng 1991. Aristotle and the stasis theory: A reexamination. - Rhetoric Society Quarterly, kd 21, nr 1 (talv), lk 53-59.

Lor a ux, Nicole 2006. The Divided City: On Memory and Forgetting in Ancient Greece. New York: Zone Books.

LSJ = Liddell, Henry George, Scott, Robert, Jones, Stuart, McKenzie, Roderick 1996. A Greek-English Lexicon: With a Revised Supplement. Oxford: Clarendon Press.

Mathieu, George, Brémond, Emile 1963. Isocrate. Discours. Kd 1. Paris: Les Belles Lettres.

Mathieu, George, Brémond, Emile 1966. Isocrate. Discours. Kd 3. Paris: Les Belles Lettres.

Minio-Paluello, Lorenzo 1966. Aristotelis categoriae et liber de interpretatione. Oxford: Clarendon Press.

Mutschmann, Hermann 1914. Sexti Empirici opera. Kd 2. Leipzig: Teubner.

$\mathrm{Nadeau}$, Ray E. 1959. Some Aristotelian and stoic influences on the theory of stases. - Speech Monographs, kd 26, nr 4 (november), lk 248-254.

N äri pä, Neeme 2011. Hermogenes Tarsosest. - Akadeemia, nr 9, lk 1681-1696. 
Näripä, Neeme 2019. Stasis: Ein antikes Konzept. (Dissertationes studiorum Graecorum et Latinorum Universitatis Tartuensis 9.) Tartu: University of Tartu Press.

Pep per, Stephen C. 1946. The descriptive definition. - The Journal of Philosophy, kd 43, nr 2, lk 29-36.

R a be, Hugo 1893. Syriani in Hermogenem commentaria. Kd 2. Leipzig: Teubner. Schenkl, Heinrich 1965. Epicteti dissertationes ab Arriano digestae. Leipzig: Teubner.

Thiele, Georg 1893. Hermagoras: ein Beitrag zur Geschichte der Rhetorik. Strassburg: Tübner.

Winterbottom, Michael 1970. M. Fabi Quintiliani institutionis oratoriae libri duodecim. Kd 1-2. Oxford: Clarendon Press.

W o er th er, Frédérique 2012. Hermagoras: Fragments et témoignages. Paris: Les Belles Lettres.

Neeme Näripä (snd 1980), Tartu Ülikooli Raamatukogu teaduskeskuse nooremteadur(W. Struwe 1, 50091 Tartu), neeme.naripa@ut.ee

\section{Philology, philosophy, and truth}

Keywords: philology, philosophy, stasis, conceptual history

On the borderline of philology and philosophy, it often happens that the two approaches collide, claiming both to be true, whatever 'true' may mean. A distinction can be made between the Platonic qualitative movement towards truth and the quantitative approach to truth inherent in modern philology. At the same time, both perspectives are culture-specific, closely related to the dominant discourse, selection principles and hierarchy. This creates obstacles, for example, in the study of conceptual history but also in philology in general. The solution is to let go of the truth to some extent, accepting its time-varying and context-sensitive nature.

Neeme Näripä (b. 1980), University of Tartu Library, Research Center, Junior Research Fellow (W. Struwe 1, 50091 Tartu), neeme.naripa@ut.ee 